\title{
Delineation of site-specific management units for operational applications using the Topographic Position Index in La Pampa, Argentina*
}

\author{
María Soledad Mieza ${ }^{1}$, Walter Rubén Cravero ${ }^{2}$, Federico Darío Kovac ${ }^{1}$, Pablo Gastón \\ Bargiano $^{3}$ \\ ${ }^{1}$ Facultad de Ingeniería, Universidad Nacional de La Pampa. Centro Universitario. (6360) Ge- \\ neral Pico. La Pampa. Argentina. smieza@ing. unlpam. edu.ar \\ ${ }^{2}$ IFISUR, Universidad Nacional del Sur, CONICET, Departamento de Física - UNS, Av. L. N. \\ Alem 1253, B8000CPB - Bahía Blanca, Argentina. wcravero@uns. edu . ar \\ ${ }^{3}$ External consultant
}

\begin{abstract}
In this work we propose the use of the topographic position index (TPI), which takes into account the local topography for a given neighborhood, to delineate management units (MU) for site-specific systems. This study was performed in the province of La Pampa, in central Argentina, an area with sandy soils where the main limiting condition for crops is soil moisture. Usually, multi-annual yield maps are used for the delineation of MU. However, those are strongly influenced by issues that could be related to un-calibrated data and previous agronomical practices. Thus, there was a need for a methodology based on stable and unbiased parameters. The methodology was developed for a representative 100 ha field. The average size and orientation of the topographic structures were characterized applying the autocorrelation function on the topographic data, which was then used to determine an optimum neighborhood size for the TPI. TPI performed better than the topographic map to characterize the variability of the field. The correlation between yield and TPI was higher $(r$ $=0.74)$ than that between yield and topography $(r=0.54)$. The resulting management units were delineated using an unsupervised classification approach on the TPI maps. From the confusion matrices, the overall accuracy was higher for the TPI derived maps than for the topography derived maps (62\% against $47 \%$ ) when compared to a yield map used as reference. We estimate that this methodology could be used for operational applications, the only requirement being topographic data for a given field, since it is simple, the algorithms used are unbiased and it could be performed using free software.
\end{abstract}

Keywords: Site Specific Management; Precision Farming; Management Unit; Topographic Position Index (TPI); Autocorrelation Function; Argentina

*Publicado en Computers and Electronics in Agriculture.(2016) 127, 158-167. http://dx.doi.org/10.1016/j.compag.2016.06.005 